\title{
Produções criativas de matrizes e de transformações geométricas com metodologias ativas
}

Creative productions of matrices and geometric transformations with active methodologies

\author{
Greiton Toledo de Azevedo ${ }^{1}$ \\ Marcus Vinícius Maltempi ${ }^{2}$
}

\section{Resumo}

Nosso objetivo é compreender o processo de aprendizagem de matrizes e suas transformações geométricas: Reflexão, Translação, Escala e Rotação. Norteados pelas Metodologias Ativas de Aprendizagem, a produção de dados foi realizada no curso de Redes em Computadores Integrado ao Ensino Médio, com os alunos do $2^{\circ}$ ano do Instituto Federal Goiano, em Ipameri/GO. O cenário formativo de aprendizagem foi criado como lugar para vivenciar experiências em matemática como modo de vida e não como ação mecânica e formalismos, que tendem a minar a forma de pensar, inventar e criar do próprio aluno em relação à aplicação de matrizes e as suas transformações geométricas. Os dados foram produzidos em sala de aula, usando malha quadriculada, GeoGebra e quadro-branco, e foram analisados a partir de elementos do Construcionismo identificados nas atividades mobilizadas. Os resultados obtidos indicam os conhecimentos construídos a partir da mobilização de ideias matemáticas e da produçãoargumentação-compreensão do conteúdo de matrizes e transformações, evidenciando a importância da aprendizagem ativa e problematizada-contextual pelos alunos.

Palavras-chave: Construcionismo. Matriz. Aprendizagem matemática. Metodologia ativa.

\section{Introdução}

Renomados teóricos na Educação e Educação Matemática já evidenciavam preocupações quanto à forma de ensinar e aprender no século 20. Entre eles, destacamos Seymour Papert (1994), que reforçava os princípios das metodologias ativas de aprendizagem a partir da pedagogia de projetos, de modo a valorizar a experiência do aluno em seu processo formativo, evidenciando a conexão entre os diferentes saberes sem se reduzir à transmissão de

\footnotetext{
${ }^{1}$ Doutorando em Educação Matemática na Universidade Estadual Paulista (Unesp). Docente do Instituto Federal Goiano, Ipameri, GO - Brasil. e-mail: greiton.azevedo@ifgoiano.edu.br.

${ }^{2}$ Livre-Docente em Educação Matemática pela Universidade Estadual Paulista (Unesp). Professor do Programa de Pós-Graduação em Educação Matemática da Unesp de Rio Claro, SP - Brasil. email: marcus.maltempi@unesp.br.
} 
conhecimento. No Brasil, Paulo Freire (1981) também criticou a abordagem descontextualizada do currículo, propondo a formação do aluno a partir de experiências de exploração e investigação, para além do conteúdo fracionado.

Neste sentido, tendo em vista a realidade da sala de aula, propusemos um conjunto de atividades "mão na massa" que fosse além do conteúdo conceitual e procedimental, buscando por um processo formativo atual, ativo e criativoargumentativo no estudo de matrizes e transformações geométricas. As produções dessas matrizes, junto aos alunos do $2^{\circ}$ ano em Redes de Computadores Integrado ao Ensino Médio (EM), do Instituto Federal Goiano (IFGoiano), em Ipameri/GO, buscou contribuir com o processo de aprendizagem, despertar o protagonismo e a criatividade dos alunos pela matemática.

Tal busca pauta-se nas ideias em torno das Metodologias Ativas de Aprendizagem (MAA), que oferecem oportunidade para revigorar e revalidar a tradição construcionista da Educação (RESNICK, 2017) a partir da argumentaçãoreflexão e do pensar-sobre-o-próprio-pensar, que carrega características do Construcionismo (PAPERT, 2008) e privilegia as ideias da Aprendizagem Criativa (RESNICK, 2017). Desta forma, este trabalho propõe-se a compreender o processo de aprendizagem de matemática do aluno do EM a partir da produção de Matrizes e suas Transformações Geométricas.

Evidenciamos, no primeiro momento, em fragmento-recortes, a formação contextual e ativo-engajada do aluno, pautando-se no Construcionismo (PAPERT, 2008; AZEVEDO, 2017; AZEVEDO et al. 2018, 2019; MALTEMPI, 2012). No segundo momento, destacamos as produções criativas das matrizes e suas transformações geométricas desenvolvidas pelos alunos, ressaltando as ideias específicas e gerais da matemática subjacentes a cada uma delas.

\section{Matrizes e suas transformações geométricas}

O trabalho realizado com a produção de matrizes associadas às transformações geométricas, que passa por uma série de etapas, vai além de conceitos isolados e rígidos. É uma proposta que não se resume ao conteúdo: 
possibilita o questionamento, a reflexão e o trabalho colaborativo criativocientífico. Os conteúdos podem estar estrategicamente amalgamados às competências da Base Nacional Comum Curricular (BNCC) de modo a incentivar os alunos a: interpretar e representar a localização e o deslocamento de uma figura no plano cartesiano; identificar transformações isométricas; e produzir ampliações e reduções de figuras.

As atividades aliadas à MAA buscam favorecer a interpretação e compreensão de matrizes e suas operações e transformações geométricas. Cabe ressaltar que, historicamente, a concepção de matriz surgiu depois das noções de sistemas lineares, determinantes, transformações lineares e formas quadráticas. O assunto "matriz" foi anunciado pelo matemático britânico James Joseph Sylvester (1814-1897), em 1850, em um artigo publicado no Philosophical Magazine (SYLVESTER, 1850b), voltado a uma situação-problema da Geometria. As suas operações surgiram depois, sendo apresentadas pelo estudioso Arthur Cayley (1821-1895). As definições apresentadas por estes matemáticos se mantiveram e são comumente exploradas em sala de aula e encontram-se nos documentos oficiais da Educação Básica.

Discordando de reduzir o estudo de matrizes aos processos meramente procedural e técnico-formal ou mecânico, o nosso entendimento é que, ao trabalhar com este assunto na Educação Básica, a organização dos processos de ensino e aprendizagem a partir de MAA, em sala de aula, deve exigir nova postura tanto do professor quanto do aluno frente à construção de conhecimento matemático, em um ambiente de diálogo, pesquisa e desenvolvimento de ideias exploratório-criativas; um processo visto como produção ativa que permita ao estudante desenvolver o seu potencial criativo e a sua capacidade de verbalizar e de enfrentar ativamente diferentes situações-problema, em vez de apenas receber informações prontas a serem consumidas ou reproduzidas.

Em vez de definição-exemplo-exercícios-respostas, as ações de aprendizagem podem valorizar a compreensão-invenção-resultados quanto ao conteúdo de matrizes e suas transformações geométricas. A ideia aqui não é a de 
focar no conteúdo em si mesmo, mas de oportunizar um processo formativo maior, tendo como base as características do saber e fazer matematicamente, entre as quais se destacam: desenvolver ideias; lidar com o imprevisto; propor soluções para um problema encaminhado e estabelecer relações conceituais.

É nesse sentido que lançamos luz à compreensão da produção de matrizes e suas transformações geométricas. Um trabalho didático-pedagógico e investigativo-reflexivo que oferece não só novas estratégias de ensino, mas que possibilite ao aluno ter formação mais ativa e menos isolada no que se refere ao conteúdo explorado em sala de aula a partir de MAA.

\section{Metodologias Ativas de Aprendizagem}

As Metodologias Ativas de Aprendizagem (MAA) buscam promover 0 processo formativo do aluno, privilegiando a sua autonomia, investigação e a sua criatividade ao construir conhecimentos científicos e empíricos sem se reduzir ao compasso do treinamento de conteúdos curriculares. É um processo biunívoco de aprendizagem no qual tanto os alunos como o professor interpretam o seu meio, levantam hipóteses, analisam contextos e constroem junto-engajadamente ideias e o conhecimento mobilizado (AZEVEDO, 2017). Algumas iniciativas de diversas partes do mundo procuram tornar o aprendizado mais relevante e atual para os alunos a partir desse tipo de metodologia em seus mais diferentes contextos de aprendizagem associando as ideias do jardim de infância (RESNICK, 2017).

A aprendizagem caracterizada no jardim de infância, que passa pelas mãos e carrega ideias e características das MAA, acaba se associando à ideia de brincadeiras com blocos, atividades para modelar, que dão origem a invenções curiosas e potencialmente criativas. As ações de ensino e aprendizagem podem se originar como possibilidades de descobertas e invenção para o professor e aluno e, portanto, não devem ser deixadas de lado no decorrer de sua trajetória escolar em níveis mais avançados. "Em vez de fazer jardim de infância como o resto da trajetória escolar, nós precisamos fazer o resto da escola (na verdade, o 
resto da vida) mais como o jardim de infância" (RESNICK, 2017, p. 17, tradução nossa), que favorece a investigação, a curiosidade e a criatividade.

A ideia aqui não é a de reduzir o ensino e a aprendizagem de matemática do EM ao manuseio de materiais concretos, construção de blocos ou até mesmo na manipulação de massinhas. O resgate das concepções do jardim de infância vai além dessa compreensão e se efetiva no fato de oportunizar situações desencadeadoras de invenção e aprendizagem ativa ao aluno de tal modo que ele possa ser capaz de: criar novas ideias em conjunto; estabelecer novas relações do conteúdo; desenvolver projetos de interesse pessoal; e ser capaz de interpretar e propor soluções a problemas encaminhados de forma criativa - ser um pensador criativo. Assim, "[...] o processo de se tornar um pensador Criativo "com C maiúsculo" é em si um processo interativo" (RESNICK, 2017, p. 5, tradução nossa), que conjuga elementos de formação mais ativo-participativa.

Desta forma, olhamos para a criatividade de matrizes à luz das ideias da Aprendizagem Criativa (RESNICK, 2017; AZEVEDO et al. 2018), como processo inventivo caracterizado pela imaginação, originalidade e criação-produção de artefatos curiosos, que não obedecem a uma lógica linear de passos prefixados. Assim, o processo de produzir criativamente é uma proposta que impulsiona diferentes experiências "mão na massa", pautando-se pela insubordinação ao treino do conteúdo e aprendizagem sem sentido em sala de aula.

A hierarquia procedimental conteúdo-exemplo-exercícios é rompida nessa concepção, dando lugar à inquietação e à curiosidade a partir da experimentação do aluno, na qual o processo de aprendizagem ativo passa a ser tão fundamental quanto o seu produto final. Este processo, portanto, não pode ser encarado como ação separada da formação do aluno ou que deve ser encerrado no jardim de infância. É um movimento que pode ser encorajado e consolidado ao longo da trajetória formativa do aluno, evidenciando a relevância das MAA em matemática.

Olhamos às MAA como processo ativo e participativo de aprendizagem do aluno, que não recebe nada pronto nem tampouco mastigado pelo professor, negando-se, portanto, a ideia que um bom caminho para a aprendizagem se 
reduza ao aperfeiçoamento da mera instrução ou do acúmulo excessivo do ensino. A partir desta interpretação, entendemos que a MAA dialoga fortemente com as ideias preconizadas pelo Construcionismo, referencial teórico que norteia as nossas ações pedagógico-científicas e teórico-filosóficas.

\section{Construcionismo}

Ainda que os alunos possam apresentar boas notas ou excelentes resultados, muitas vezes não estão preparados para os desafios inesperados que encontram após a formatura, em suas vidas profissionais e em suas vidas pessoais (RESNICK, 2017). Segundo este autor "[...] muitos alunos aprendem a resolver tipos específicos de problemas, mas são incapazes de se adaptar e improvisar em resposta a situações inesperadas que inevitavelmente surgem no mundo em rápida mudança de hoje" (RESNICK, 2017, p. 18, tradução nossa). É nesse sentido que damos enfoque à compreensão da aprendizagem de matrizes e suas transformações geométricas à luz das ideias construcionistas.

O Construcionismo é uma teoria de aprendizagem que considera que o desenvolvimento cognitivo é um processo ativo de construção das estruturas mentais, no qual o conhecimento não pode ser simplesmente transmitido de uma pessoa para outra (PAPERT, 2008; AZEVEDO, 2017, AZEVEDO et al., 2018). "O processo de aprendizado deve ser um processo ativo, em que os aprendizes 'colocam a mão na massa' no desenvolvimento de projetos de forma ativa, em vez de ficarem sentados atentos a fala do professor" (MALTEMPI, 2012, p. 288).

Nenhum conhecimento, o que inclui o de matemática, conforme Lévy (1999, p. 79), "[...] pode ser depositado de maneira incólume na cabeça do aluno de forma a caracterizar uma transmissão direta". Todo o conhecimento sofre relações na cabeça do aluno, que podem "[...] ser corretas, ricas, perenes ou não dependendo especialmente do trabalho do professor, quando consideramos 0 ambiente escolar" (MALTEMPI, 2012, p. 3). Concordamos com essas ideias, pois não acreditamos que conhecimento possa ser transmitido, porque não é possível de ser recebido pronto, acabado, sem transformação. Pelo contrário, ele é 
(re)construído a partir de vivências ocorridas com o meio social, que se mostra permeado pelas múltiplas e complexas interações estabelecidas, carecendo, portanto, ser (re) feito por cada indivíduo.

Desta forma, nosso entendimento quanto à aprendizagem de matemática na visão construcionista, em especial, a partir das MAA em sala, não é vista como ato minimalista de transferência de conhecimento do professor para o aluno. $O$ aluno despoja-se da postura de mero ouvinte para assumir a participação ativa e comprometida com sua aprendizagem. À luz desta compreensão, avançamos à próxima seção, destacando o contexto e o percurso metodológico deste trabalho.

\section{0 contexto e o percurso metodológico}

Tendo assumido o processo de aprendizagem em matemática que privilegia as ideias do Construcionismo amalgamadas às MAA a partir da produção de matrizes e suas transformações geométricas, este trabalho é norteado pelos pressupostos qualitativos de pesquisa, pois busca "[...] atingir aspectos humanos sem passar pelos crivos da mensuração, sem partir de métodos previamente definidos e, portanto, sem ficar presos a quantificadores e aos cálculos recorrentes" (BICUDO, 2006, p. 107).

A pesquisa foi realizada em sala de aula ao longo de três encontros, cada um deles com duração de 140 minutos, com a participação de 25 alunos do EM do IF-Goiano, em Ipameri/GO. Neste artigo trazemos inicialmente a produção criativa de matrizes e suas transformações geométricas e, no segundo momento, evidenciamos dois recortes, Cenários $A$ e $B$, das duas principais etapas sequenciais desenvolvidas sobre matrizes e suas transformações em sala de aula.

Para registro dos dados, utilizamos diversos instrumentos, como diário de campo (professor), fotografias e filmagens. Utilizaremos recortes-fragmentos dos diálogos-discussões gravados e anotados, bem como faremos uso de [...] para explicitar trecho que se refira à transcrição de fala dos autores. Para a análise dos dados em relação à compreensão do processo da aprendizagem do conteúdo de 
matrizes e suas transformações geométricas, utilizamos as ideias preconizadas pelo Construcionismo, lançando luz às concepções prático-filosóficas das MAA. É buscando a atualização dessa visão construcionista à aprendizagem de matrizes e transformações, que partimos para a próxima seção, na qual apresentamos as produções criativas dos alunos e a parte matemática ali envolvida.

\section{Produções criativas de matrizes e suas transformações}

Evidenciamos as produções criativas das matrizes e suas transformações geométricas (Translação, Reflexão, Escala, Rotação) desenvolvidas pelos alunos, dando sentido e contexto à aprendizagem de matemática. Nesta seção, exemplificamos quatro modelos de transformações geométricas produzidas pelos alunos no estágio final. A ideia aqui é destacar os trabalhos de transformações produzidos por eles e tecer ideias gerais e específicas de matemática de tais produções para futuros trabalhos a serem realizados em sala de aula.

\section{Matriz Capitão América (CA) | Transformação Geométrica | TRANSLAÇÃo}

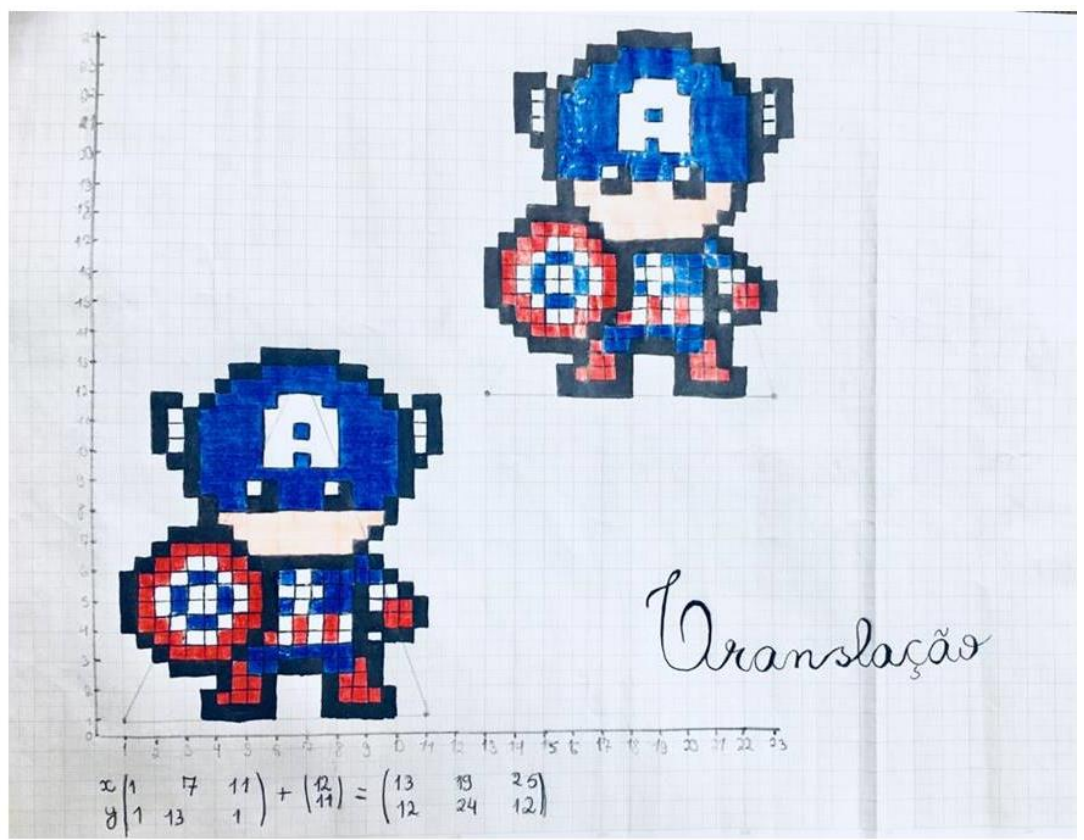

O que há por trás do desenho matricial-artístico? Adição de Matrizes e Translações horizontal e vertical 


$$
A=\left(\begin{array}{ccc}
1 & 7 & 11 \\
1 & 13 & 1
\end{array}\right) \quad \stackrel{\text { Tranlação }}{\longrightarrow} \quad C A^{\prime}=\left(\begin{array}{ccc}
13 & 19 & 23 \\
12 & 24 & 12
\end{array}\right)
$$

A região A sofreu uma translação: $\left(\begin{array}{l}12 \\ 11\end{array}\right)=\left(\begin{array}{l}x \\ y\end{array}\right) \quad \begin{aligned} & 12 \text { unidades à direita ao longo do eixo } \mathrm{x} \\ & 11 \text { unidades para cima ao longo do eixo } \mathrm{y}\end{aligned}$

Uma ideia geral do esboço construído pelo grupo de alunos, para transladar um ponto $\mathrm{P}(\mathrm{x}, \mathrm{y}) \mathrm{de}$ $\boldsymbol{a}$ unidades para a direita e $\boldsymbol{b}$ unidades para cima, efetuamos a adição de matrizes:

Em símbolos, temos: $\left(\begin{array}{l}x \\ y\end{array}\right)+\left(\begin{array}{l}a \\ b\end{array}\right)=\left(\begin{array}{l}x+a \\ y+b\end{array}\right)$, x e y representam a matriz original dada (triangular).

Obs.: 0 valor $a_{13}=25$ da matriz CA' (na imagem acima) foi corrigido para $a_{13}=23$ ao longo das discussões em sala de aula. Decidimos manter o valor original apresentado pelos alunos antes da correção, evidenciando um processo ativo de idas e vindas, que conjuga erros e aprendizagem a partir deles.

Figura 1: Matriz de Translação: Capitão América

Fonte: Dados da pesquisa (2019)

\section{Matriz Homem de Ferro (HF) | Transformação Geométrica | REFLEXÃO}

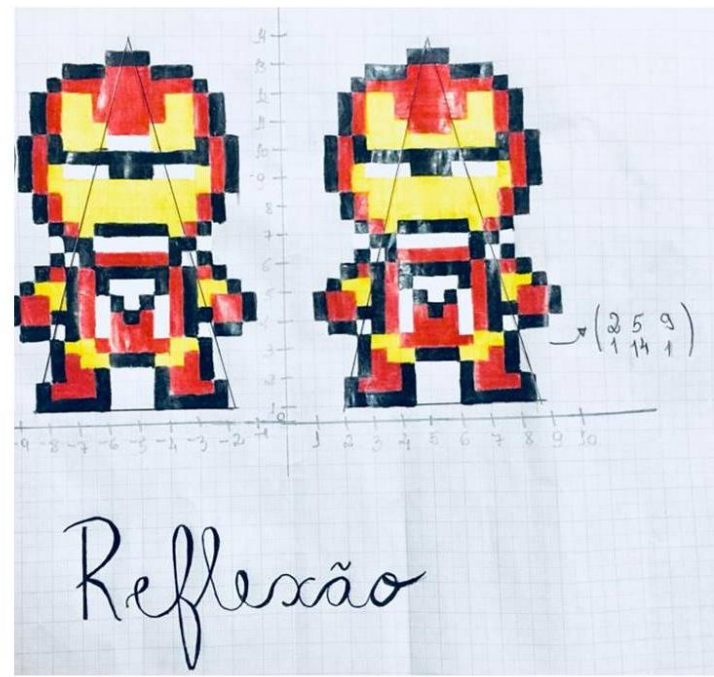

O que há por trás do desenho matricial-artístico? Multiplicação de Matrizes e reflexão em relação ao eixo y 
Vértices do polígono HF e HF', respectivamente: $(-2,1),(-5,14),(-9,1)$ e $(2,1),(5,14),(9,1)$. $A$ região $A$ (associada à figura) sofreu uma reflexão em relação em ao eixo y dando origem à região $A^{\prime}$

A reflexão que leva HF em HF' é indicada por:

$$
H F=\left(\begin{array}{ccc}
-2 & -5 & -9 \\
1 & 14 & 1
\end{array}\right) \quad \stackrel{\text { Reflexล์ด }}{\longrightarrow} \quad H F^{\prime}=\left(\begin{array}{ccc}
2 & 5 & 9 \\
1 & 14 & 1
\end{array}\right)
$$

Podemos obter a matriz de HF' multiplicando a Matriz de HF pela Matriz $\left(\begin{array}{cc}-1 & 0 \\ 0 & 1\end{array}\right)$, ou seja:

$$
\left(\begin{array}{cc}
-1 & 0 \\
0 & 1
\end{array}\right) \times\left(\begin{array}{ccc}
-2 & -5 & -9 \\
1 & 14 & 1
\end{array}\right)=\left(\begin{array}{ccc}
2 & 5 & 9 \\
1 & 14 & 1
\end{array}\right)
$$

De modo genérico, para obter a reflexão em relação ao eixo y de uma figura cuja matriz associada dada, por exemplo, por: $\left(\begin{array}{lllll}a & b & c & d & e \\ f & g & h & i & j\end{array}\right)$, basta efetuar o produto:

$$
\left(\begin{array}{cc}
-1 & 0 \\
0 & 1
\end{array}\right) \times\left(\begin{array}{lllll}
a & b & c & d & e \\
f & g & h & i & j
\end{array}\right)=\left(\begin{array}{ccccc}
-a & -b & -c & -d & -e \\
f & g & h & i & j
\end{array}\right)
$$

Obs.: o grupo de alunos escolheu a reflexão em y, porém, é possível fazer a reflexão em $x$.

Figura 2: Matriz de Reflexão: Homem de Ferro

Fonte: Dados da pesquisa, 2019.

\section{Matriz Tartaruga Ninja (T) | Transformação Geométrica | ESCALA}

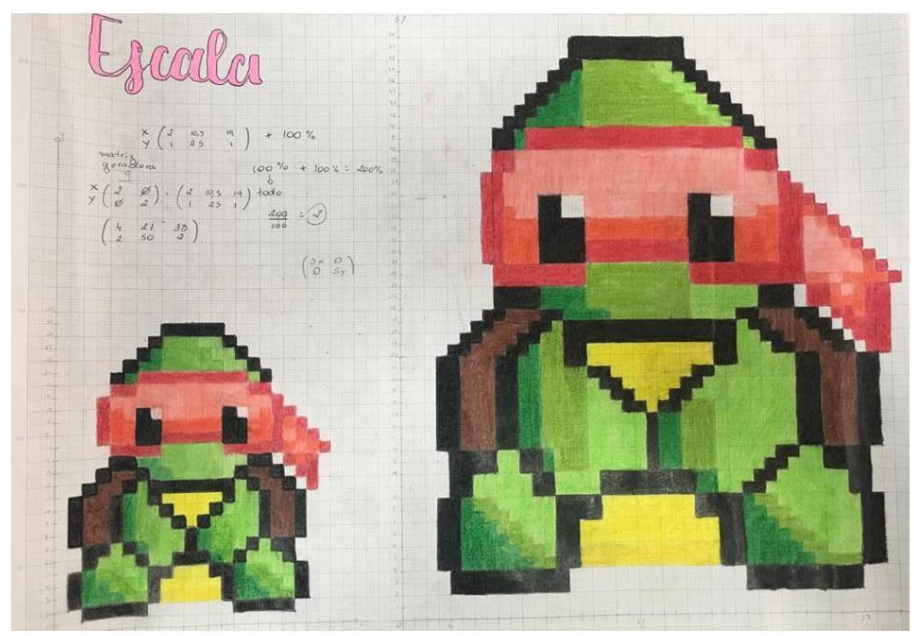

O que há por trás do desenho matricial-artístico? Ampliação e redução proporcional de figuras 
Seja uma mudança de escala de um ponto $P(x, y)$ em relação, usando um fator mulplicativo $T_{x}$, para coordenada $x$ e um fator mulplicativo $T_{y}$ para a coordenada $y$. Assim, temos $A=\left(\begin{array}{cc}T x & 0 \\ 0 & T y\end{array}\right)$ e a matriz $\mathrm{B}=\left(\begin{array}{l}x \\ y\end{array}\right)$, assim sendo, devemos ter: $\mathrm{B}^{\prime}=\mathrm{A} \times \mathrm{B}$. No registro acima dos alunos, temos:

$$
\left(\begin{array}{ll}
2 & 0 \\
0 & 2
\end{array}\right) \times\left(\begin{array}{ccc}
2 & 10,5 & 19 \\
1 & 25 & 1
\end{array}\right)=\left(\begin{array}{ccc}
4 & 21 & 38 \\
2 & 50 & 2
\end{array}\right)
$$

Observa-se que o grupo usou o primeiro quadrante para expressar intuitivamente a escala do desenho, fazendo uso de diferentes representações simbólicas pessoais do conteúdo. Desta forma, valores ficaram positivos. Percebe-se também que o desenho foi aumentado $100 \%$. Assim sendo, os valores de $T_{x}=T_{y}=2$. Isso se justifica, pois, aumentar $100 \%$ nas direções dos eixos $O_{x}$ e $\mathrm{O}_{\mathrm{y}}$, é o mesmo que multiplicar por 2 , da mesma forma que aumentar $70 \%$ é multiplicar por 1,7 , etc. Vale ressaltar que a matriz original associada sempre representará $100 \%=100 / 100=1$.

De modo genérico, podemos escrever uma matriz de escala:

$$
\left(\begin{array}{cc}
\text { Tx } & 0 \\
0 & \text { Ty }
\end{array}\right) \times\left(\begin{array}{ccc}
a & b & c \\
f & g & h
\end{array}\right)=\left(\begin{array}{ccc}
-a & -b & -c \\
f & g & h
\end{array}\right) \text {, sendo a matriz associada dada }\left(\begin{array}{lll}
a & b & c \\
f & g & h
\end{array}\right) \text {. }
$$

Figura 3: Matriz de Escala: Tartaruga Ninja Fonte: Dados da pesquisa, 2019.

\section{Matriz Dead Pool (DP) | Transformação Geométrica | ROTAÇÃO}

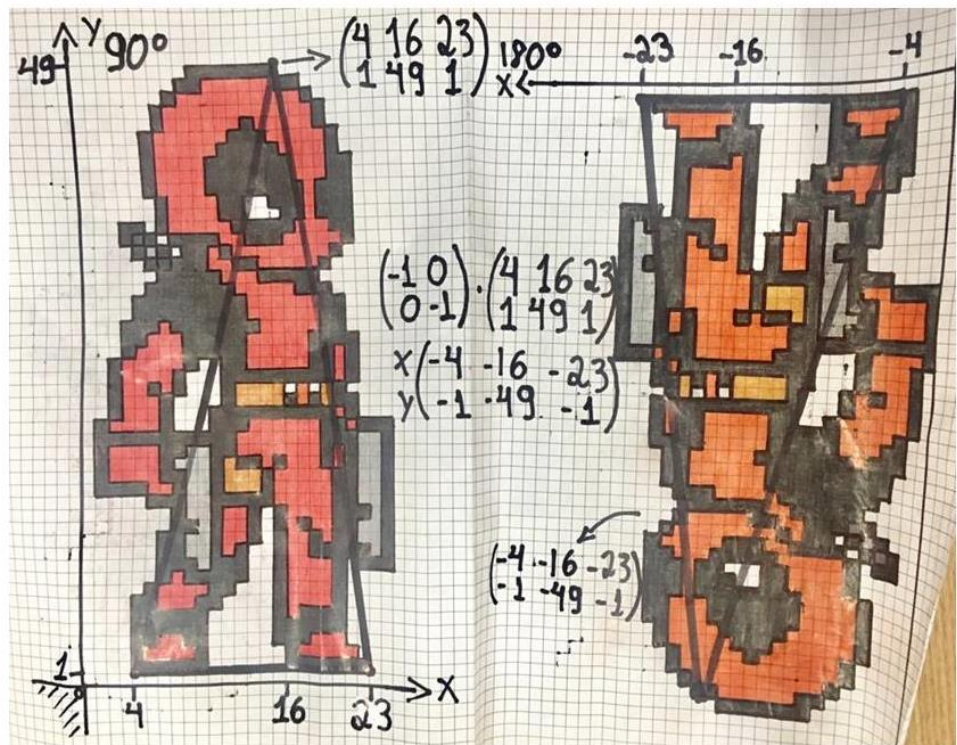

O que há por trás do desenho matricial-artístico? Rotação, ângulos e funções trigonométricas. 
A figura DP (à esquerda) sofre uma rotação de $180^{\circ}$ no sentido anti-horário, dando origem à figura DP' (à direita). As matrizes DP e DP' são respectivamente:

$$
\left(\begin{array}{ccc}
4 & 16 & 23 \\
1 & 49 & 1
\end{array}\right) \text { e }\left(\begin{array}{ccc}
-4 & -16 & 23 \\
-1 & -49 & 1
\end{array}\right)
$$

Encontramos DP' multiplicando a matriz original pela matriz $\left(\begin{array}{cc}-1 & 0 \\ 0 & -1\end{array}\right)$, que é correspondente a:

$\left(\begin{array}{cc}\cos 180^{\circ} & -\operatorname{sen} 180^{\circ} \\ \operatorname{sen} 180^{\circ} & \cos 180^{\circ}\end{array}\right)$, ou seja: $\left(\begin{array}{cc}-1 & 0 \\ 0 & -1\end{array}\right) \times\left(\begin{array}{ccc}4 & 16 & 23 \\ 1 & 49 & 1\end{array}\right)=\left(\begin{array}{ccc}-4 & -16 & 23 \\ -1 & -49 & 1\end{array}\right)$.

Para dedução dos ângulos, os alunos foram incentivados a analisar o círculo trigonométrico:

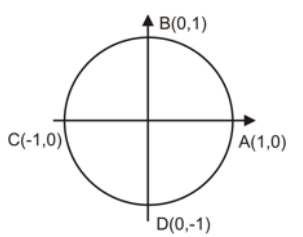

De modo geral, para se obtiver a rotação de $\beta$ grau no sentido anti-horário em torno da origem $(0,0)$ de uma figura na qual a matriz original é dada, por exemplo, $\left(\begin{array}{lll}a & b & c \\ d & e & f\end{array}\right)$, basta efetuar o produto, a saber:

$$
\left(\begin{array}{cc}
\cos \beta & -\operatorname{sen} \beta \\
\operatorname{sen} \beta & \cos \beta
\end{array}\right) \times\left(\begin{array}{lll}
a & b & c \\
d & e & f
\end{array}\right)
$$

Figura 4: Matriz de Escala: Dead Pool

Fonte: Dados da pesquisa, 2019.

\section{Cenário A: Matriz associada à Transformação (Escala)}

A sala foi organizada para ser um ambiente de invenções, questionamentos e deduções-lógicas e intuitivas de matemática. Os alunos foram separados em trios e quartetos para pensar-junto e desenvolver as ações propostas. A ideia inicial era de relacionar as matrizes ao plano cartesiano a partir de figuras geométricas simples, como triângulos, quadrados, etc. Encorajamos os alunos a pensar na estrutura da matriz associada aos pontos $\mathrm{P}(\mathrm{x}, \mathrm{y})$ no Plano cartesiano e suas operações, tendo como apoio o uso do GeoGebra, quadrobranco e papéis-quadriculados, que auxiliaram nas produções alinhado-simétricas das figuras.

Em sequência, exploramos as transformações (Translação, Reflexão, Escala e Rotação) de um objeto qualquer (quadrado, triângulo, losango, trapézio, etc.) no quadro. Decidimos não seguir a explicação receita-bolo do tipo: faça isso 
e depois faça aquilo. Pelo contrário, os alunos foram incentivados a pensar, argumentar e analisar as transformações geométricas das figuras associadas as suas matrizes correspondentes a partir de questões norteadoras. Uma dessas ações didático-investigativas pode ser observada no fragmento-recorte a seguir.

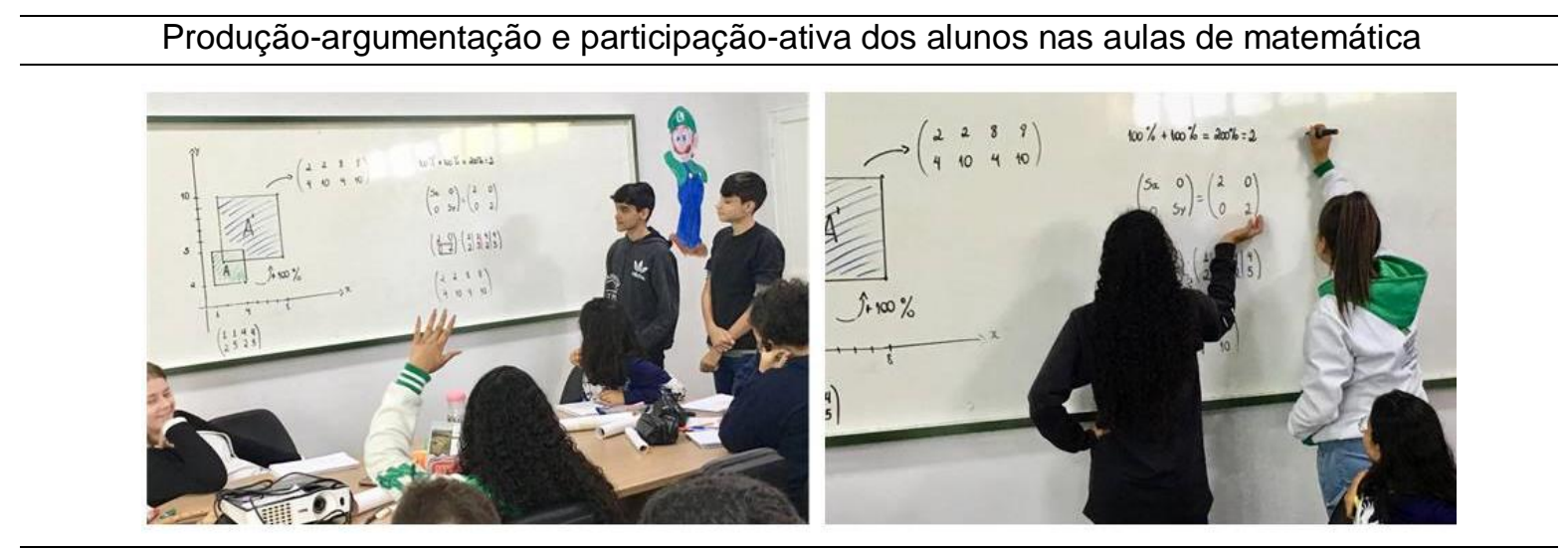

Prof.: Como podemos aumentar a região desse quadrado em $100 \%$ associado à matriz? Pense um pouco: O que deve acontecer com as suas dimensões e os valores dos elementos dessa nova matriz? [discussão] Guímel: [Alguns minutos depois] Nosso grupo pensou algumas ideias para a matriz A. Percebemos que 0 coeficiente da matriz geratriz será igual a 2, pois já temos $100 \%$ da matriz dada [Matriz A] e mais $100 \%$ de aumento, então, deve ser igual a $200 \%$.

[Registro do Quadro-Branco, $\mathrm{A}=\left(\begin{array}{cccc}1 & 1 & 4 & 4 \\ 2 & 5 & 2 & 5\end{array}\right) \stackrel{T}{\rightarrow} A^{\prime}=\left(\begin{array}{cccc}2 & 2 & 8 & 8 \\ 4 & 10 & 4 & 10\end{array}\right)$ ].

Taynara: Os elementos dobram de valor. Mas, o legal é que a sua área não dobra, quadruplica.

Prof.: Refletindo sobre a fala da Taynara: $O$ que seria essa nova área associada à matriz?

José G: (...) a área do quadrado verde cabe exatamente quatro vezes na área do quadrado azul. As "dimensões do desenho" são duplicadas, assim como os elementos da matriz. [Explica-discute-argumenta com os colegas a matriz gerada, $\mathrm{B}=\left(\begin{array}{ll}2 & 0 \\ 0 & 2\end{array}\right)$; matriz geradora].

Guímel: Então por isso que os nossos cálculos estavam errados [Refaz o produto das Matrizes] [Ideias intuitivas à formalização: $\mathrm{B} \times \mathrm{A}=\mathrm{A}^{\prime}=\left(\begin{array}{ll}2 & 0 \\ 0 & 2\end{array}\right) \times\left(\begin{array}{llll}1 & 1 & 4 & 4 \\ 2 & 5 & 2 & 5\end{array}\right)=\left(\begin{array}{cccc}2 & 2 & 8 & 8 \\ 4 & 10 & 4 & 10\end{array}\right)$ ].

Figura 5: Discussão-compreensão da Matriz associada à transformação Escala Fonte: Dados da pesquisa, 2019.

A fala "[...] Nosso grupo pensou [...] percebemos que o coeficiente [...] então, deve ser igual a 200\% [...]", - evidencia a relação de ideias geradas pelos alunos quanto à produção-reflexão-argumentação da matriz associada à transformação de escala, relacionando conteúdos específicos de porcentagem. A ideia aqui não é a de unir termos de matemática e reduzir ao conteúdo procedimental do tipo: faça isso e repita 50 vezes depois. Pelo contrário, a 
essência, que se apresenta, neste caso, está na forma de conduzir o processo de testar hipóteses para forjar ideias ativamente pelos alunos (PAPERT, 2008).

Há um contexto de argumentação ativa, que ocorre processo de busca, de erros e até mesmo de dificuldades superadas ao longo do trabalho, como evidencia os excertos: "Os elementos dobram de valor. Mas, o legal é que [registra no quadro] a sua área não dobra, quadruplica" [e] "As "dimensões do desenho" são duplicadas, assim como os elementos da matriz [explica a matriz gerada]". Observa-se o processo ativo para compreensão do conteúdo que se amplia durante a argumentação e produção dos alunos. Tal processo, segundo as ideias construcionistas, acaba estruturando-se pela mobilização de ideias a partir da compreensão de significados de matemática à formalização de termos específicos relacionados (AZEVEDO et al, 2018).

A compreensão do conteúdo como forma de aprendizagem é um processo dinâmico e marcado por passos não lineares e nem pré-definidos, constituindo-se por idas e vindas, discussão-reflexões, bem como por avanços e retrocessos de ideias. Tal processo pode ser observado no seguinte excerto: "então por isso que os nossos cálculos estavam errados (...) a matriz geradora tem de ser (...)". O processo aqui não é conhecido a priori e nem dado de forma verticalizada pelo professor, há um esforço de engajamento de ambos os atores para a procura da resposta, exigindo deles uma postura ativa em sala tanto para mobilização de significados quanto para a compreensão, no caso da matriz geradora.

A proposta de quebrar com a aula de conceito-exemplos e listas de exercícios, à luz do Construcionismo, não significa diminuir a responsabilidade do professor e deixar o aprendiz fazer o que quiser. Na verdade, é um movimento que pressupõe a parceria de ambos durante o processo de produção e argumentação de significados, de ideias e contextos. Essa busca pela mudança tem por finalidade, "[...] descentralizar o foco excessivo do conteúdo procedimental matemático, que muitas vezes se reduz aos aspectos mecânicos e, ao mesmo tempo, privilegiar espaços associados à investigação, à exploração, à participação e à construção de ideias coletivas" (AZEVEDO, 2017, p. 36). 
Este cenário apresenta a construção de significados pelos alunos sendo mediados pelo professor, que promove um espaço de discussão e registros favoráveis à compreensão da matriz escalar relacionando-a a uma figura proporcional. O processo não se resume a explicação do professor, enquanto todo restante se mostra inerte, ou seja, não se limitou ao domínio de técnicas, memorização mecânica e atividades receituário-fechadas. $O$ aluno pode buscar significado pela pesquisa, discussão e debate ao lado do professor, até porque, mesmo quando parece estarmos transmitindo com sucesso informações dizendoas, "se pudéssemos ver os processos cerebrais em funcionamento, observaríamos que nosso interlocutor está reconstruindo uma versão pessoal das informações que pensamos estar transferindo" (PAPERT, 2008, p. 137).

Para além do fragmento-recorte apresentado, a seção subsequente evidencia a segunda etapa de argumentação e produção ativa pelos alunos, relacionando as ideias de matrizes, transformações e seus cálculos com as produções (desenhos criativos) no papel quadriculado. Tal etapa constituiu-se como espaço de pesquisa e de orientação quanto às produções já encaminhadas pelos grupos. Assim sendo, avançamos à próxima seção para entender melhor esse espaço.

\section{Cenário B: Matriz associada à Transformação (Rotação)}

$\mathrm{Na}$ segunda etapa, os alunos foram incentivados a apresentar e argumentar as ideias de matrizes associadas as transformação geométricas à luz da produção de: rascunhos de figuras em forma de pixels na malha quadriculada. Os alunos escolheram os desenhos que gostariam de desenvolver e, a partir disso, estruturávamos, em conjunto, a matriz de parametrização ao desenho, tendo por base cálculos correspondentes das matrizes na malha quadriculada.

O desafio, para os alunos, não foi o cálculo, mas as proporções que deveriam ser respeitadas para a elaboração de cada desenho. Um processo que demandou esforço, dedicação e reflexão-criativa tanto na produção das formas quanto na pintura. Reforçamos que as ações didático-pedagógicas baseavam-se 
na perspectiva de valorizar o gosto pessoal dos alunos pelos personagens e, principalmente, de incentivar o trabalho em equipe da produção criativa. Trazemos um recorte-fragmento a seguir, exemplificando um desses momentos.

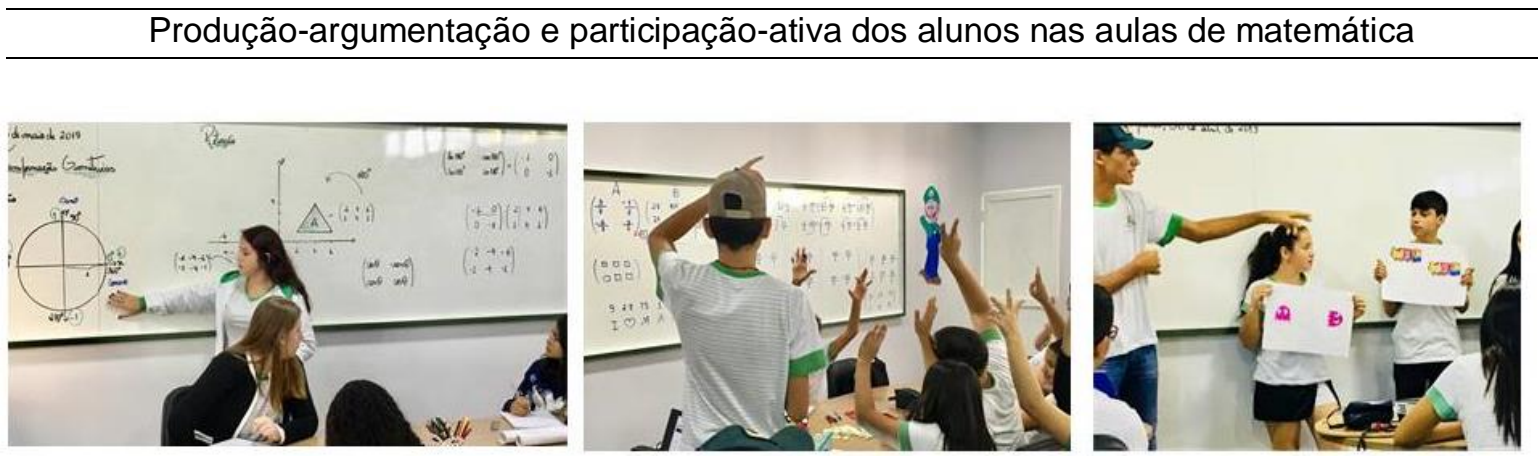

Gabriela: Estamos gostando de projetar as figuras no papel. Mas, já erramos mil vezes [som de risos]. Matheus: Está dando certo. O nosso grupo tem feito alguns desenhos de base. (...) "Rotacionar", aqui, é virar a figura a partir da rotação da matriz. Por exemplo, o quadrante 1 [plano cartesiano] é a posição da figura base, se virarmos 90 graus para esquerda [sentido anti-horário] ela vai ficar "deitada" no segundo quadrante [mostra a figura]. Se forem 180 graus, a figura vai para o terceiro quadrante e fica "de cabeça para baixo" [invertida], e assim sucessivamente.

Gabriela: Como já exploramos as figuras mais simples, estamos usando a mesma ideia de ângulo aqui (...). Matheus: Ah, por isso que usamos a função de trigonometria na matriz geradora, porque tem de fazer girar. Professor: (...) Precisamos construir uma matriz geradora de tal modo que envolva esses conceitos. Como vocês estão pensando para usar a matriz geratriz para fazer os desenhos girarem?

Gabriela: Percebemos que as projeções estão melhores de serem visualizadas, usando os ângulos notáveis do círculo [trigonométrico], daí, fizemos as correções para fazer os desenhos no quadriculado.

Figura 6 - Discussão-compreensão da Matriz associada à transformação Rotação Fonte: a pesquisa, 2019.

A fala "(...) estamos gostando de projetar as figuras no papel. Mas, já erramos mil vezes", demonstra o engajamento da aluna quanto à produção criativa da matriz na malha quadriculada. Há um produto de significado pessoal, que é explorado, refletido e discutido pela aluna ao compartilhá-lo. Muito além de aprender fazendo, nesse contexto, o Construcionismo acrescenta: “(...) aprendese melhor ainda quando se gosta, pensa, discute e conversa sobre o que se faz" (MALTEMPI, 2005, p. 3).

As ideias matemática aparecem como pano de fundo da construção engajado-participativa das matrizes pelo grupo. Uma dessas ideias intuitivas aparece na argumentação-explicação-produção do aluno: “(...) Rotacionar, aqui, é 
virar a figura a partir da rotação da matriz. Por exemplo, o quadrante 1 é a posição da figura base, se virarmos 90 graus para esquerda, ela vai ficar "deitada" no segundo quadrante (...)". Existe um conceito formal envolvido por trás da fala do aluno: existe uma matriz geradora $A$ de tal modo que se multiplicá-la pela matriz $B$ [matriz base], o resultado será a Matriz resultante $[C=A \times B]$.

Não foi o professor explicando na sala de aula ou o aluno copiando e repetindo tudo que estava ali no quadro-branco. Ambos desenvolviam juntos. $O$ papel do professor estava ali, no lugar certo: o do lado do aluno, ajudando-o e encorajando-o a pensar em novos caminhos, a corrigir os erros a analisar novas possibilidades para resolver um problema encaminhado da intuição-exploração à compreensão-formalização. À luz deste entendimento, o Construcionismo preconiza que não se pode atingir a aprendizagem apenas reduzindo-se ao ensino, enquanto, porém, todo o restante se mostra inalterado em sala de aula.

A atitude construcionista no ensino "[...] não é, em absoluto, dispensável por ser minimalista - a meta é ensinar de forma a produzir a maior aprendizagem [ativa] a partir do mínimo de instrução" (PAPERT, 2008, p. 134). O conhecimento mobilizado se mostra presente na discussão-compartilhada entre os alunos, valorizando as ideias intuitivas até os conceitos mais específicos, como se observa no excerto: "por isso que usamos a função de trigonometria na matriz geradora, porque tem de fazer girar". Entendemos que há uma associação entre ideias intuitivas e ideias mais gerais, como no caso da matriz de referência associada à trigonometria. Há um processo que prestigia o intuitivo, que passa pela discussão-argumentação até à formalização do conteúdo mobilizado.

Trabalhar com formalismos e signos que não possuem nexos de significados para o aluno, pode comprometer o processo de aprendizagem dele. Entendemos que o importante não é só o ponto de chegada, nem somente o ponto de partida, mas um todo complexo de sua construção-significado. Para esse entendimento, recuperamos a fala da aluna que diz: "(...) as projeções ficaram melhor de serem visualizadas (...) fizemos as correções (...)”. O processo 
aqui é aliado à aprendizagem, pois ao surgir erros ao longo da atividade ela pôde refletir sobre ele e teve a chance de propor estratégias para corrigi-lo.

Nesse sentido, as atividades que acontecem nesse processo de discussão, que leva em conta as MAA, partem da premissa que essas ideias/hipóteses transitórias de aprendizagem, levantadas pelos alunos, se constituem um fator importante no processo de criação da matriz e da produção de significados das transformações. Isso porque a depuração de ideias possibilita ao estudante não só refletir sobre o desenho construído ou o cálculo realizado, mas também o permite pensar nos erros e a partir deles avançar no processo de compreensão.

Percebemos, porém, que não é só dominar os conceitos estudados, tampouco explorá-los durante a construção de uma matriz na malha quadriculada, mas a partir deles ter a oportunidade de criar novas coisas, ter a oportunidade de discutir sobre elas com outras pessoas, favorecendo assim "[...] a troca de ideias e opiniões que podem auxiliar e impulsionar o aprendiz a desenvolver projetos mais complexos que envolvam novos conhecimentos" (PAPERT, 1994, p. 127). E é justamente essa troca de ideias e a assimilação de novos conceitos que carregaram um sentido prático de estar ali fazendo-criando e aprendendo.

\section{Palavras finais}

Buscamos compreender o processo de aprendizagem de matrizes e suas transformações geométricas à luz do Construcionismo e das Metodologias Ativas de Aprendizagem, destacando o estudo das produções criativas das matrizes (CA, HF, TN, DP). A interação com os estudantes e os discursos apresentados evidenciam um processo contextualizado e não linear de ideias fixas, que exige do estudante e, ao mesmo tempo, permite que eles sigam seus interesses.

O propósito de construir personagens em forma de matrizes não era deixar o processo de aprendizagem "bonitinho" ou superficial em termos conceituais e procedimentais. Mas, objetivamos oportunizar aos alunos a compreensão das ideias matemáticas específicas sobre matrizes e suas transformações, dando-lhes a chance de escolher e inventar desenhos de seu interesse pessoal e estabelecer 
relações entre o conteúdo matemático, com autonomia e criatividade ao longo das MAA.

O contexto foi dado pelos estudantes ao associarem personagens de seu interesse ao estudo de matriz, favorecendo o engajamento deles nas diversas ações criadas e envolvidas no estudo. A dinâmica das aulas inibia a passividade dos estudantes, desafiando-os a tomar e controlar suas decisões, a compartilhálas e, nesse processo, as avaliarem. O estudo de matriz, portanto, não se resumia a procedimentos e dava sentido para que a comunicação, a colaboração e a criatividade ocorressem.

Sendo assim, esperamos contribuir com a prática docente de professores de matemática da Educação Básica que desejam seguir abordagens ativas, valorizando aspectos da compreensão-invenção-resultados em vez de atividades do tipo receita ou do modelo definição-exemplo-exercícios do conteúdo. Os diálogos e as matrizes apresentadas podem inspirar esses professores a valorizar a formação de seus alunos, para além do ato de fazer uma prova e, por consequência, conseguir uma boa nota. É um trabalho que busca focar mais na aprendizagem do que no conhecimento como fim em si mesmo.

\section{Agradecimentos}

Aos queridos alunos do $2^{\circ}$ ano do IF-Goiano, Campus Avançado Ipameri, pela dedicação contínua nas aulas e nos projetos de matemática. Ao Antonio Netto Junior pela revisão do texto.

\section{Referências}

AZEVEDO, Greiton Toledo de. Construção de conhecimento matemático a partir da produção de jogos digitais em um ambiente construcionista de aprendizagem: possibilidades e desafios. Dissertação (Mestrado em Educação em Ciências e Matemática) - Universidade Federal de Goiás, Goiânia, Goiás, 2017.

AZEVEDO, Greiton Toledo de; MALTEMPI, Marcus Vinicius; RIBEIRO, José Pedro Machado; LYRA, Gene Maria Vieira. Produção de Games nas Aulas de Matemática: Por que não? Revista Acta Scientiae, Canoas (RS), v. 20, n. 5, p. 950-966, 2018.

AZEVEDO, Greiton Toledo de; MALTEMPI, Marcus Vinicius; LYRA-SILVA, Gene Maria Vieira. Processo formativo do aluno em matemática: jogos digitais e tratamento de 
Parkinson. Zetetiké (On Line), Campinhas (SP), v. 26, p. 569-585, 2018.

AZEVEDO, Greiton Toledo de; MALTEMPI, Marcus Vinicius.; LYRA, Gene Maria Vieira. Computacional Thinking and Active Learning in Mathematics as a contribution to the treatment of Parkinson's disease. In: Science and Mathematics Education in The 21st Century. Braga, Portugal: University of Minho, 2019.

BICUDO, Maria Aparecida Viggiani. Pesquisa Qualitativa e Pesquisa Qualitativa Segundo a Abordagem Fenomenológica. In: BORBA, Marcelo de Carvalho; ARAÚJO, J. L. (Org.).

Pesquisa Qualitativa em Educação Matemática. São Paulo: Autêntica, 2006. p. 100-118.

FREIRE, P. (1981). Pedagogia do Oprimido. Rio de Janeiro: Paz e Terra.

MALTEMPI, Marcus Vinicius. Novas Tecnologias e Construção de Conhecimento: Reflexões e perspectivas. In: CONGRESSO IBERO-AMERICANO DE EDUCAÇÃO MATEMÁTICA, 5., Porto, Anais [...] Porto: CIBEM, 2005.

LÉVY, Pierre. Cibercultura. Rio de Janeiro: Editora 34, 1999.

MALTEMPI, Marcus Vinicius. Construcionismo: pano de fundo para pesquisas em informática aplicada à Educação Matemática. In: BICUDO, Maria Aparecida Viggiani.; BORBA, Marcelo de Carvalho. (Org.). Educação Matemática: pesquisa em movimento. São Paulo: Cortez, 2012. p. 287-307.

PAPERT, Seymour. A máquina das Crianças: repensando a escola na era informática. Porto Alegre: Artes Médicas, 2008.

PAPERT, Seymour. Instrucionismo versus Construcionismo. In: PAPERT, Seymour. A máquina das crianças: repensando a escola na era da informática. Porto Alegre: Artes Médicas, 1994.

RESNICK, Mitchel. Lifelong Kindergarten: cultivating Creativity through projects, passion, peers and play. 1. ed. Cambridge, Ma: MIT Press, 2017.

SYLVESTER, James Joseph. (1851c). On the Relation between the Minor Determinants of Linearly Equivalent Quadratic Functions. In: BAKER, H. F. 1904. The Collected

Mathematical Papers of James Joseph Sylvester. Cambridge: University Press, 1904. v. 1. p. 241-250. 